Chronic Obstructive Pulmonary Diseases: Journal of the COPD Foundation

Review

\title{
Alpha-1 Antitrypsin Substitution for Extrapulmonary Conditions in Alpha-1 Antitrypsin Deficient Patients
}

\author{
Boris M. Baranovski, MSc ${ }^{1}$ Ronen Schuster, $\mathrm{PhD}^{1}$ Omer Nisim, BLabMed ${ }^{1}$ Ido Brami, BMedSci ${ }^{1}$ \\ Yotam Lior, BMedSci ${ }^{1}$ and Eli C. Lewis, $\mathrm{PhD}^{1}$
}

\begin{abstract}
Alpha-1 antitrypsin deficiency (AATD) is a genetic disorder which most commonly manifests as pulmonary emphysema. Accordingly, alpha-1 antitrypsin (AAT) augmentation therapy aims to reduce the progression of emphysema, as achieved by life-long weekly slow-drip infusions of plasma-derived affinity-purified human AAT. However, not all AATD patients will receive this therapy, due to either lack of medical coverage or low patient compliance. To circumvent these limitations, attempts are being made to develop lung-directed therapies, including inhaled AAT and locally-delivered AAT gene therapy. Lung transplantation is also an ultimate therapy option. Although less common, AATD patients also present with disease manifestations that extend beyond the lung, including vasculitis, diabetes and panniculitis, and appear to experience longer and more frequent hospitalization times and more frequent pneumonia bouts. In the past decade, new mechanism-based clinical indications for AAT therapy have surfaced, depicting a safe, anti-inflammatory, immunomodulatory and tissueprotective agent. Introduced to non-AATD individuals, AAT appears to provide relief from steroid-refractory graft-versus-host disease, from bacterial infections in cystic fibrosis and from autoimmune diabetes; preclinical studies show benefit also in multiple sclerosis, ulcerative colitis, rheumatoid arthritis, acute myocardial infarction and stroke, as well as ischemia-reperfusion injury and aberrant wound healing processes. While the current augmentation therapy is targeted towards treatment of emphysema, it is suggested that AATD patients may benefit from AAT augmentation therapy geared towards extrapulmonary pathologies as well. Thus, development of mechanism-based, context-specific AAT augmentation therapy protocols is encouraged. In the current review, we will discuss extrapulmonary manifestations of AATD and the potential of AAT augmentation therapy for these conditions.
\end{abstract}

Abbreviations: alpha-1 antitrypsin deficiency, AATD; alpha-1 antitrypsin, AAT; chronic obstructive pulmonary disease, COPD; graftversus-host-disease, GVHD; cystic fibrosis, CF; myocardial infarction, MI

Funding Support: NA

Date of Acceptance: March 29, 2018

Citation: Baranovski BM, Schuster R, Nisim O, Brami I, Lewis EC. Alpha-1 antitrypsin substitution for extrapulmonary conditions in alpha-1 antitrypsin deficient patients. Chronic Obstr Pulm Dis. 2018;5(4):267-276. doi: https://doi.org/10.15326/jcopdf.5.4.2017.0161

1 Department of Clinical Biochemistry and Pharmacology, Faculty of Health Sciences, Ben-Gurion University of the Negev, BeerSheva, Israel

\section{Keywords:}

autoimmunity; bone-marrow transplantation; cell survival; diabetes; immune system; inflammation; leukemia; organ transplantation; ulcerative colitis; wound healing

\section{Address correspondence to:}

Eli C. Lewis, $\mathrm{PhD}$

Department of Clinical Biochemistry \& Pharmacology

Faculty of Health Sciences

Ben-Gurion University of the Negev

POB 151, Be'er-Sheva 8410501, Israel

Phone: ++972-8-6244-574

e-mail: lewis@bgu.ac.il 


\section{Introduction}

\section{Genetic Alpha-1 Antitrypsin Deficiency is More Than a Lung Condition}

Alpha-1 antitrypsin deficiency (AATD) is a genetic disorder caused mainly by homozygosity for the Z allele of the SERPINA1 gene. This severe form of AATD is associated with an accumulation of alpha- 1 antitrypsin (AAT) in hepatocytes that fails to reach desired levels in the circulation, eventually leading to a variety of clinical symptoms of which pulmonary emphysema is most noted. AATD individuals tend to develop chronic obstructive pulmonary disease (COPD) at a young age, perhaps explaining the overall high lung graft survival rates within this group (6.2 years for AATD and 5.3 years for non-AATD-related COPD). ${ }^{1}$ Since uncontrolled neutrophil elastase activity is considered a pivotal factor in the development of emphysema in
AATD patients, inhibiting neutrophil elastase activity and delaying the progression of emphysema has been the primary endpoint of AAT augmentation therapy for patients with AATD in the past several decades. ${ }^{2-4}$

The state-of-the-art approach for treating lung disease in genetic AATD is comprised of weekly slow-drip infusions of plasma-derived human AAT at $60 \mathrm{mg} / \mathrm{kg}$. This treatment protocol maintains serum AAT levels of at least $11 \mu \mathrm{M}$, a concentration that is presumably protective to the lung in the event of neutrophil elastase-related damage. Intravenous AAT augmentation therapy for AATD was approved by the U.S. Food and Drug Administration in the United States in 1988, and soon after by regulatory agencies around the world. Table 1 summarizes the current international guidelines for the indication of AAT augmentation therapy.

\section{Table 1. Current International Guidelines and Criteria for Alpha-1 Antitrypsin Augmentation Therapy}

The Spanish Society of $\bullet$ Age $\geq 18$ years.

Pulmonology and Thoracic Surgery
- AATD levels $\leq 35 \%$ of the normal values.

- PiZZ phenotype or rare deficient variants.

- Abstinence from smoking for at least six months.

- Pulmonary emphysema confirmed by clinical profile accompanied by $\mathrm{FEV}_{1} / \mathrm{FVC}$

$<0.70$ and $\mathrm{FEV}_{1}<80 \%$.

- Confirmation of accelerated loss of pulmonary function in non-index cases.

- Exclusion of associated IgA deficiency.

- Patient's commitment to the treatment.
The Medical and Scientific Advisory Committee of the Alpha-1 Foundation
- Individuals with an $\mathrm{FEV}_{1}$ less than or equal to $65 \%$ predicted. discussion with each individual regarding the potential benefits of reducing lung function decline with consideration of the cost of therapy and lack of evidence for such benefit.

- Individuals with necrotizing panniculitis.

Intravenous augmentation therapy is not recommended for:

- Individuals with the MZ genotype of AATD.

- Individuals with lung disease due to AATD who continue to smoke.

- Individuals with AATD and emphysema or bronchiectasis who do not have air flow obstruction.

- The treatment of liver disease due to AATD.

- Individuals who have undergone liver transplantation. 
Additional recommendations regarding dosing of intravenous augmentation therapy:

- Weekly doses higher than the current FDA-approved dose are not recommended.

- Monitoring of trough AAT blood levels to evaluate the adequacy of AAT augmentation dosing is not recommended.

The American Thoracic

Society and the European

Respiratory Society

National Institute for

Health and Care

Excellence

Canadian Thoracic

Society
- The use of intravenous augmentation therapy for individuals with established airflow obstruction from AATD.

- Patients identified as having AATD should be offered the opportunity to be referred to a specialist center to discuss the clinical management of this condition.

- AAT replacement therapy is not recommended for patients with AATD.

- AAT augmentation therapy may be considered in non-smoking or ex-smoking patients with $\mathrm{COPD}$ ( $\mathrm{FEV}_{1} 25 \%$ to $80 \%$ predicted) attributable to emphysema and documented AATD (level $\leq 11 \mu \mathrm{M})$, who are receiving optimal pharmacological and nonpharmacological therapies (including comprehensive case management and pulmonary rehabilitation) because of benefits in CT scan lung density and mortality.

$\mathrm{AATD}=$ alpha- 1 antitrypsin deficiency; $\mathrm{FEV}_{1}=$ forced expiratory volume in 1 second; $\mathrm{FVC}=$ forced vital capacity; AAT=alpha- 1 antitrypsin; $\mathrm{COPD}=$ chronic obstructive pulmonary disease

Present-day protocol carries inherent limitations: the financial burden associated with life-long plasmaderived AAT infusions often prevents authorities from granting financial drug coverage to this rare condition, thus limiting drug availability. ${ }^{10}$ In addition, patient compliance is suboptimal considering the lifelong requirement for weekly visitations at an infusion center. Considering that AATD is a relatively underdiagnosed condition and the recent appreciation of some several-fold more individuals who carry one of many forms of AAT insufficiency, including heterozygote AATD and patients with mutated alleles of $A A T,{ }^{11}$ it would be an understatement to conclude that, presently, not all AATD patients receive AAT augmentation therapy.

Apart from emphysema, AATD is also associated with extrapulmonary manifestations. ${ }^{12,13}$ These include liver diseases, such as cirrhosis and chronic hepatitis, as well as various forms of vasculitis, diabetes and panniculitis. ${ }^{13}$ Several issues can be raised if one considers the extrapulmonary manifestation of AATD. Can non-COPD patients with diagnosed AATD benefit from AAT augmentation therapy? If so, would the current treatment protocol be suitable for such conditions, considering the collection of unique end-points unrelated to emphysema? This article will review the clinical indications for AAT augmentation therapy that address extrapulmonary conditions secondary to AATD, which are presently not covered by existing practice guidelines or systematic reviews.

\section{Discussion}

\section{The Therapeutic Potential of Alpha-1 Antitrypsin Beyond Inhibition of Neutrophil Elastase}

The therapeutic repertoire of AAT has been revisited in the past decade and its attributes appear to extend beyond the protection of lung tissue from neutrophil elastase-related damage. ${ }^{14-16}$ In gut-associated graft-versus-host-disease (GVHD), AAT therapy has provided phenomenal positive outcomes in both preclinical and clinical trials. ${ }^{17-23}$ A positive trend is also observed with AAT administration to patients with acute myocardial infarction ${ }^{24}$ following impressive preclinical data. ${ }^{25-27}$ The failure of endogenous AAT levels to display an appropriate rise has been linked to poor cardiac prognosis ${ }^{28}$ and to pregnancy complications. ${ }^{29-32}$ Organ and cell transplantation studies in animals exhibit positive outcomes when supplemented with AAT therapy, ${ }^{33}$ and are presently under evaluation in multiple clinical trials. Other immune-related conditions that respond well to AAT in preclinical studies include rheumatoid arthritis, ${ }^{34}$ systemic lupus erythematosus, ${ }^{35}$ multiple sclerosis, ${ }^{36}$ type 1 autoimmune diabetes ${ }^{37}$ and ulcerative colitis, ${ }^{38}$ 
the latter suggested to be a common comorbidity of AATD. ${ }^{39}$ With regards to diabetes, 3 clinical trials have recently depicted a positive trend in protection of pancreatic cell death, precluded mostly by sample size and large patient diversity. ${ }^{40-42}$ In addition, conditions of ischemia-reperfusion injury, such as renal acutetubular necrosis and brain stroke, respond well to AAT therapy in respective animal studies. ${ }^{43-47}$

\section{Alpha-1 Antitrypsin Therapy for Improving Transplantation Outcomes}

AAT therapy has been extensively investigated in preclinical pancreatic islet transplantation studies. For example, AAT monotherapy $(60 \mathrm{mg} / \mathrm{kg})$ was reported to prolong allogeneic islet graft survival, as well as induce antigen-specific regulatory $\mathrm{T}$ cell expansion and promote strain specific tolerance. ${ }^{48,49}$ These studies lay the platform for subsequent studies relating to organ transplants. Indeed, AAT is being explored in clinical trials for islet transplantation and lung transplantation (NIH clinical trial registries NCT02614872 and NCT02520076). ${ }^{50}$

Lung transplantation is an established procedure for AATD patients in cases of end-stage pulmonary disease. According to a 2014 report of the International Society for Heart and Lung Transplantation, 6\% of adult lung-grafted patients between 1995-2012 were individuals diagnosed with AATD, as opposed to $33 \%$ who were AAT-replete graft recipients. ${ }^{51}$ In a U.S. study, post-transplantation lung function, prevalence and severity of acute cellular graft rejection, as well as survival rates, were compared between AATD lung graft recipients and AAT-replete COPD lung graft recipients. ${ }^{52}$ While the study did not find differences in post-transplantation forced expiratory volume in the single-lung-grafted patients, AATD patients who received a double-lung transplant displayed significantly faster decline rates in spirometric lung functions after transplantation. Of note, $13.3 \%$ of AATD patients received augmentation therapy after lung transplantation. It is common practice to abandon AAT augmentation therapy after lung transplantation in AATD patients, as recommended by the American Thoracic Society/European Respiratory Society guidelines. ${ }^{7}$ However, while these individuals might have intact lung-derived AAT, their liver-derived systemic AAT levels remain below normal. Thus, for AATD patients who receive lung transplants, AAT therapy should be considered during related systemic
AATD manifestations.

\section{Alpha-1 Antitrypsin Therapy for Bacterial Infections}

AAT has been shown to reduce P. aeruginosa bacterial burden in the lungs and circulation of infected mice, ${ }^{53}$ a finding that was reproduced in multi-strain bacterial peritonitis and sepsis models. ${ }^{54}$ Accordingly, AATtreated AATD patients were found to experience lower rates of bacterial pneumonia ${ }^{55}$ and inhalation of AAT was shown to reduce bacterial burden in the lungs of cystic fibrosis (CF) patients. ${ }^{56}$ These studies show that native AAT does not inhibit bacterial growth in culture, but rather modulates the host immune system. In addition, AAT turns antibacterial upon direct exposure to high levels of local nitric oxide, which is abundant in infected tissues. ${ }^{54}$

While COPD is a well-documented manifestation of AATD, AATD patients seem to suffer from a higher frequency of exacerbations compared to Global Initiative for Obstructive Lung Disease-staging controlled non-AATD COPD patients ${ }^{13,57}$; AATDpatients experience about 2 moderate-to-severe annual exacerbations ${ }^{58,59}$ compared to one annual exacerbation in non-AATD COPD patients. ${ }^{60}$ These COPD exacerbations were associated with pneumonia and suggested to be in line with greater mortality rates ${ }^{61}$ and longer hospitalization periods ${ }^{13}$ than nonAATD COPD cases. AATD patients are commonly instructed to use face-masks in public places, regardless of whether or not they are treated with AAT. Indeed, several studies have found that AATD patients were more likely to suffer from higher pulmonary bacterial loads, ${ }^{62}$ bronchiectasis, ${ }^{63-65}$ chronic polypoid sinusitis ${ }^{66}$ and mycobacterial abscesses ${ }^{67}$ compared to non-AATD individuals. Moreover, patients who suffer from both AATD and CF were more likely to develop chronic bacterial colonization with $P$. aeruginosa earlier in life, compared to nonAATD CF patients. ${ }^{68}$ Further research is required to establish the effect of AAT on bacterial infections in AATD individuals, yet short-term AAT augmentation should be considered in cases of bacterial infections or as preconditioning prior to immunosuppression in cases such as transplantation. 


\section{Alpha-1 Antitrypsin Therapy for Expediting Wound Healing}

Dermatological manifestations that are associated with AAT deficiency include panniculitis, vasculitis, psoriasis, urticaria and angioedema. ${ }^{7}$ A common denominator with respect to all these conditions can be described as the inability of skin tissue to resolve inflammation and achieve tissue repair.

Panniculitis is one of the most studied, skin-related AATD clinical phenotypes. Similar to emphysema, it has been suggested that the underlying cause of panniculitis is a dysregulated inflammatory process in the skin. ${ }^{69-71}$ A case study of a 31-year-old with PiZZ AATD-related panniculitis demonstrated the presence of Z-type AAT in the skin ${ }^{72}$; the same study reports that high dose, long-term augmentation therapy reduced both frequency and severity of the skin-related disease.

Resolution of inflammation is an essential step in the wound healing process. ${ }^{73}$ Considering the antiinflammatory properties of AAT and its physiological rise during acute phase responses and late stages of pregnancy, it is reasonable to predict that AATD patients will be more susceptible to episodes of unresolved inflammation. Should this unresolved inflammation occur in blood vessel walls, vasculitis may develop and in turn lead to skin ulceration and delayed wound healing. ${ }^{74}$

This notion is exemplified by a recent case study in which a severe postoperative wound healing disturbance was depicted in a 50-year-old untreated AATD patient; the stagnant wound was resolved once AAT augmentation therapy was initiated. ${ }^{75}$ The authors of that study suggest weighing AAT augmentation therapy in all AATD patients as part of perioperative treatment protocols.

Experiments with AAT therapy in preclinical studies suggest that AAT augmentation therapy can accelerate wound healing rates and reduce the penumbra effect following ischemic injury in both cardiac and cerebral tissues. ${ }^{27,46}$ Accordingly, a recent clinical trial found that AAT augmentation therapy in non-AATD patients diagnosed with ST elevation myocardial infarction (MI) significantly reduced C-reactive protein levels, as well as displayed overall improved cardiac function, suggesting that the repair process of the injured cardiac tissue was somewhat superior under AAT augmentation, ${ }^{24}$ agreeing with previous observations of improved prognosis in acute MI patients who had high circulating levels of AAT. ${ }^{28}$
Taken together, whether one regards a case of a non-healing skin wound or an internal injury, it is possible that untreated AATD patients will experience some compromised form of tissue self-repair, and that supplementing their treatment protocols around such an event with AAT infusions may address this difficulty. In addition, considering that the major outcome used to challenge augmentation therapy efficacy has been lung emphysema, one must contemplate whether the weekly bolus approach holds optimal biological function when it comes to the intricate process of wound healing.

\section{Not All Alpha-1 Antitrypsin Deficiency Patients Receive Alpha-1 Antitrypsin Augmentation Therapy}

Some countries do not provide AAT augmentation therapy. In others, low patient compliance may render the treatment immaterial. This phenomenon may be greater than presently conceived, considering the emergence of relative AAT insufficiency in the form of heterozygote deficiency and inactive variants of AAT. In addition, AAT levels are known to rise during inflammation; a subclinical episode of inflammation may increase serum AAT levels, thus masking true baseline AAT levels. ${ }^{78}$ This is specifically important in the case of heterozygote deficiency, since some MZ individuals may in fact have low levels of AAT $(<80 \mathrm{mg} / \mathrm{dl})$ and thus may be eligible for augmentation treatment. Indeed, heterozygote AATD individuals are also at risk for developing lung and skin-associated manifestations. ${ }^{71,77-79}$

With these hurdles in mind, it is proposed that AAT therapy may be justified if not for life, then for a medical circumstance: transplantation procedures, elective susceptibility to infections and events of tissue wounding are a few of a list of examples for clinical conditions that might warrant periodic AAT augmentation irrespective of compliance towards a life-long treatment plan.

\section{When and How Much?}

Augmentation therapy protocols are presently designed to satisfy a diminished risk for emphysema. However, based on the collective research from the past decade, therapy should be tailored for each clinical context in which a patient with AATD happens to be involved. If the presently afforded regimen satisfies lower emphysema rates down the 
line, does it also necessarily address the benefits of AAT preconditioning for transplant surgery? Does the protocol support wound repair? Minimize diabetes? Protect nerve cells or cardiomyocytes from ischemia-reperfusion injury? The pharmacokinetics of weekly AAT infusions is one of a short spike in AAT followed by a prolonged low trough before the next infusion session takes place. ${ }^{40,80}$ While this protocol may postpone the advent of emphysema, it does not represent the physiological steady-state production of AAT in non-deficient individuals or healthy pregnancies. $^{81,82}$ In addition, it does not represent inducible levels of AAT during inflammation or other conditions that are not related to neutrophil elastase imbalance. The work by Baranovski et al provided a high-resolution examination of AAT dosing and routes of administration for cell survival, a condition that represents a non-emphysema-associated endpoint. ${ }^{83}$ More research should be undertaken in order to explore the possibility of condition-specific AAT augmentation protocols.

\section{Why is Alpha-1 Antitrypsin Deficiency Not Associated with Every Condition That is Presently Emerging as Responsive to Exogenous Alpha-1 Antitrypsin Therapy?}

There is a phenomenal redundancy in the functions of SERPINs; lacking one may be compensated by others, depending on the function at hand. It is highly probable that other SERPINs hold clinical benefits, yet these proteins are either not available yet, or otherwise may hold adverse outcomes (e.g., antithrombin III). The fact that raising the level of AAT in some medical conditions provides advantage to the struggling tissues, may represent a mere peek at the capacity of the organism to heal.

It is owing to the rare condition of genetic AATD that we are presently aware of this protein as a legitimate clinical tool, both diagnostic and therapeutic. AATD has provided us with decades of prolonged clinical use that has laid the safety concern to rest. We must now point AAT therapy towards a more mechanistic, context-specific and physiological-oriented clinical application.

\section{Acknowledgments}

We dedicate this review to the groundbreaking medical science visionary, Prof. Charles A. Dinarello, who has the ever-expanding basic research realm relentlessly gravitate towards the clinical realm.

\section{Declaration of Interest}

All authors of this manuscript declare no conflict of interest. 


\section{References}

1. Christie JD, Edwards LB, Kucheryavaya AY, et al. The Registry of the International Society for Heart and Lung Transplantation: 29th adult lung and heart-lung transplant report-2012. J Heart Lung Transplant. 2012;31(10):1073-1086. doi: https://doi.org/10.1016/j.healun.2012.08.004

2. Rahaghi FF, Miravitlles M. Long-term clinical outcomes following treatment with alpha 1-proteinase inhibitor for COPD associated with alpha-1 antitrypsin deficiency: a look at the evidence. Respir Res. 2017;18:105.

doi: https://doi.org/10.1186/s12931-017-0574-1

3. Tortorici MA, Rogers JA, Vit O, Bexon M, et al. Quantitative disease progression model of alpha-1 proteinase inhibitor therapy on computed tomography lung density in patients with alpha-1 antitrypsin deficiency. $\mathrm{Br} \mathrm{J}$ Clin Pharmacol. 2017;83(11):2386-2397.

doi: https://doi.org/10.1111/bcp.13358

4. Chapman KR, Burdon JG, Piitulainen E, et al. Intravenous augmentation treatment and lung density in severe alpha1 antitrypsin deficiency (RAPID): a randomised, double-blind, placebo-controlled trial. Lancet. 2015;386(9991):360-368. doi: https://doi.org/10.1016/S0140-6736(15)60860-1

5. Vidal R, Blanco I, Casas F, Jardi R, Miravitlles M, Committee on the National Registry of Individuals with Alpha-1 Antitrypsin Deficiency. Guidelines for the diagnosis and management of alpha-1 antitrypsin deficiency [in Spanish]. Arch Bronconeumol. 2006;42(12):645-659.

doi: https://doi.org/10.1157/13095974

6. Sandhaus RA, Turino G, Brantly ML, et al. The diagnosis and management of alpha-1 antitrypsin deficiency in the adult. Chronic Obstr Pulm Dis. 2016;3(3):668-682.

doi: https://doi.org/10.15326/jcopdf.3.3.2015.0182

7. American Thoracic Society, European Respiratory Society. American Thoracic Society/European Respiratory Society statement: standards for the diagnosis and management of individuals with alpha-1 antitrypsin deficiency. Am J Respir Crit Care Med. 2003;168(7):818-900.

doi: https://doi.org/10.1164/rccm.168.7.818

8. National Institute for Health and Care Excellence (NICE). Chronic obstructive pulmonary disease in over 16s: diagnosis and management. NICE website. https://nice.org.uk/guidance/cg101 Published 2010. Accessed March 2018.

9. Marciniuk DD, Hernandez P, Balter M, et al. Alpha-1 antitrypsin deficiency targeted testing and augmentation therapy: a Canadian Thoracic Society clinical practice guideline. Can Respir J. 2012;19(2):109-116. doi: https://doi.org/10.1155/2012/920918

10. Karl FM, Holle R, Bals R, et al. Costs and health-related quality of life in alpha-1 antitrypsin deficient COPD patients. Respir Res. 2017;18:60. doi: https://doi.org/10.1186/s12931-017-0543-8
11. McElvaney NG. Diagnosing alpha-1antitrypsin deficiency: how to improve the current algorithm. Eur Respir Rev. 2015;24(135):5257. doi: https://doi.org/10.1183/09059180.10010814

12. Streicher JL, Sheehan MP, Armstrong AB, Mousdicas N. Cutaneous manifestation of alpha(1)-antitrypsin deficiency: panniculitis absent on biopsy. Cutis. 2014;93(6):303-306.

13. Greulich T, Nell C, Hohmann D, et al. The prevalence of diagnosed alpha-1 antitrypsin deficiency and its comorbidities: results from a large population-based database. Eur Respir J. 2017;49(1). doi: https://doi.org/10.1183/13993003.00154-2016

14. Lewis EC. Expanding the clinical indications for alpha (1)-antitrypsin therapy. Mol Med. 2012;18:957-970. doi: https://doi.org/10.2119/molmed.2011.00196

15. Lewis E. a1-antitrypsin therapy for non-deficient individuals: integrating and mitigating cross-pathology inflammatory and immune responses to the injured cell. Intern Med Rev. 2017;3. doi: http://dx.doi.org/10.18103/imr.v3i5.451

16. Blanco I, Lara B, de Serres F. Efficacy of alpha-1antitrypsin augmentation therapy in conditions other than pulmonary emphysema. Orphanet J Rare Dis. 2011;6:14. doi: https://doi.org/10.1186/1750-1172-6-14

17. Hagen LE, Schechter T, Luk Y, Brodovitch A, Gassas A, Doyle JJ. High alpha- 1 antitrypsin clearance predicts severity of gut graftversus-host disease (GVHD) in children. Pediatr Transplant. 2011;15(6):659-663.

doi: https://doi.org/10.1111/j.1399-3046.2011.01553.x

18. Marcondes AM, Hockenbery D, Lesnikova M, et al. Response of steroid-refractory acute GVHD to alpha-1antitrypsin. Biol Blood Marrow Transplant. 2016;22(9):1596-1601. doi: https://doi.org/10.1016/j.bbmt.2016.05.011

19. Marcondes AM, Karoopongse E, Lesnikova M, et al. Alpha-1 antitrypsin (AAT)-modified donor cells suppress GVHD but enhance the GVL effect: a role for mitochondrial bioenergetics. Blood. 2014;124(18):2881-2891.

doi: https://doi.org/10.1182/blood-2014-04-570440

20. Marcondes AM, Li X, Tabellini L, et al. Inhibition of IL-32 activation by alpha-1 antitrypsin suppresses alloreactivity and increases survival in an allogeneic murine marrow transplantation model. Blood. 2011;118(18):5031-5039. doi: https://doi.org/10.1182/blood-2011-07-365247

21. O'Meara A, Kapel N, Xhaard A, et al. Fecal calprotectin and alpha-1antitrypsin dynamics in gastrointestinal GvHD. Bone Marrow Transplant. 2015;50:1105-1109. doi: https://doi.org/10.1038/bmt.2015.109

22. Tawara I, Sun Y, Lewis EC, et al. Alpha-1antitrypsin monotherapy reduces graft-versus-host disease after experimental allogeneic bone marrow transplantation. Proc Natl Acad Sci USA. 2012;109(2):564-569.

doi: https://doi.org/10.1073/pnas.1117665109 
$\overline{\text { 23. Magenau JM, Goldstein SC, Peltier D, et al. Alpha-1 antitrypsin }}$ infusion for treatment of steroid resistant acute graft-versushost disease. Blood. 2018;131(12):1372-1379. doi: https://doi.org/10.1182/blood-2017-11-815746

24. Abbate A, Van Tassell BW, Christopher S, et al. Effects of prolastin C (plasma-derived alpha-1 antitrypsin) on the acute inflammatory response in patients with ST-segment elevation myocardial infarction (from the VCU-alpha 1-RT pilot study). Am J Cardiol. 2015;115(1):8-12.

doi: https://doi.org/10.1016/j.amjcard.2014.09.043

25. Mauro AG, Mezzaroma E, Marchetti C, et al. A preclinical translational study of the cardioprotective effects of plasmaderived alpha-1 antitrypsin in acute myocardial infarction. $J$ Cardiovasc Pharmacol. 2017;69(5):273-278. doi: https://doi.org/10.1097/FJC.0000000000000474

26. Toldo S, Mauro AG, Marchetti C, et al. Recombinant human alpha- 1 antitrypsin-fc fusion protein reduces mouse myocardial inflammatory injury after ischemia-reperfusion independent of elastase inhibition. J Cardiovasc Pharmacol. 2016;68(1):27-32. doi: https://doi.org/10.1097/FJC.0000000000000383

27. Toldo S, Seropian IM, Mezzaroma E, et al. Alpha-1 antitrypsin inhibits caspase- 1 and protects from acute myocardial ischemiareperfusion injury. J Mol Cell Cardiol. 2011;51(2):244-251. doi: https://doi.org/10.1016/j.yjmcc.2011.05.003

28. Gilutz H, Siegel Y, Paran E, Cristal N, Quastel MR. Alpha 1-antitrypsin in acute myocardial infarction. $\mathrm{Br}$ Heart $\mathrm{J}$. 1983;49(1):26-29. doi: https://doi.org/10.1136/hrt.49.1.26

29. Madar T, Shahaf G, Sheiner E, et al. Low levels of circulating alpha-1 antitrypsin are associated with spontaneous abortions. J Matern Fetal Neonatal Med. 2013;26(18):1782-1787. doi: https://doi.org/10.3109/14767058.2013.801955

30. Salem SY, Shahaf G, Sheiner E, et al. Diminished activity of circulating alpha-1 antitrypsin is associated with pre-gestational isolated obesity. J Matern Fetal Neonatal Med. 2015;28(5):500503. doi: https://doi.org/10.3109/14767058.2014.925442

31. Baron J, Sheiner E, Abecassis A, et al. alpha-1 antitrypsin insufficiency is a possible contributor to preterm premature rupture of membranes. J Matern Fetal Neonatal Med. 2012;25(7):934-937.

doi: https://doi.org/10.3109/14767058.2011.600369

32. Twina G, Sheiner E, Shahaf G, et al. Lower circulation levels and activity of alpha-1 antitrypsin in pregnant women with severe preeclampsia. J Matern Fetal Neonatal Med. 2012;25(7):26672670. doi: https://doi.org/10.3109/14767058.2012.705397

33. Iskender I, Sakamoto J, Nakajima D, et al. Human alpha-1 antitrypsin improves early post-transplant lung function: Preclinical studies in a pig lung transplant model. J Heart Lung Transplant. 2016;35(7):913-921.

doi: https://doi.org/10.1016/j.healun.2016.03.006
34. Grimstein C, Choi YK, Wasserfall CH, et al. Alpha-1 antitrypsin protein and gene therapies decrease autoimmunity and delay arthritis development in mouse model. J Transl Med. 2011;9:21. doi: https://doi.org/10.1186/1479-5876-9-21

35. Elshikha AS, Lu Y, Chen MJ, et al. Alpha-1 antitrypsin inhibits dendritic cell activation and attenuates nephritis in a mouse model of lupus. PLoS One. 2016;11:e0156583.

doi: https://doi.org/10.1371/journal.pone.0156583

36. Subramanian S, Shahaf G, Ozeri E, et al. Sustained expression of circulating human alpha-1 antitrypsin reduces inflammation, increases CD4+FoxP3+ Treg cell population and prevents signs of experimental autoimmune encephalomyelitis in mice. Metab Brain Dis. 2011;26(2):107-113.

doi: https://doi.org/10.1007/s11011-011-9239-9

37. Fleixo-Lima G, Ventura H, Medini M, Bar L, Strauss P, Lewis EC. Mechanistic evidence in support of alpha1-antitrypsin as a therapeutic approach for type 1 diabetes. J Diabetes Sci Technol. 2014;8:1193-1203.

doi: https://doi.org/10.1177/1932296814547096

38. Collins CB, Aherne CM, Ehrentraut SF, et al. Alpha-1antitrypsin therapy ameliorates acute colitis and chronic murine ileitis. Inflamm Bowel Dis. 2013;19(9):1964-1973.

doi: https://doi.org/10.1097/MIB.0b013e31829292aa

39. Stone H, Pye A, Stockley RA. Disease associations in alpha-1antitrypsin deficiency. Respir Med. 2014;108(2):338-343. doi: https://doi.org/10.1016/j.rmed.2013.10.006

40. Weir GC, Ehlers MR, Harris KM, et al. Alpha-1 antitrypsin treatment of new-onset type 1 diabetes: an open-label, phase I clinical trial (RETAIN) to assess safety and pharmacokinetics. Pediatr Diabetes. 2018;19(5):945-954.

doi: https://doi.org/10.1111/pedi.12660

41. Rachmiel M, Strauss P, Dror N, et al. Alpha-1 antitrypsin therapy is safe and well tolerated in children and adolescents with recent onset type 1 diabetes mellitus. Pediatr Diabetes. 2016;17(5):351359.

doi: https://doi.org/10.1111/pedi.12283

42. Gottlieb PA, Alkanani AK, Michels AW, et al. Alpha1-antitrypsin therapy downregulates toll-like receptor-induced IL-1beta responses in monocytes and myeloid dendritic cells and may improve islet function in recently diagnosed patients with type 1 diabetes. J Clin Endocrinol Metab. 2014;99(8):E1418-1426. doi: https://doi.org/10.1210/jc.2013-3864

43. Maicas N, van der Vlag J, Bublitz J, et al. Human alpha-1 antitrypsin (hAAT) therapy reduces renal dysfunction and acute tubular necrosis in a murine model of bilateral kidney ischemiareperfusion injury. PLoS One. 2017;12:e0168981. doi: https://doi.org/10.1371/journal.pone.0168981 
44. Feng $\mathrm{Y}, \mathrm{Hu} \mathrm{L}, \mathrm{Xu} \mathrm{Q}$, et al. Cytoprotective role of alpha-1 antitrypsin in vascular endothelial cell under hypoxia/reoxygenation condition. J Cardiovasc Pharmacol. 2015;66(1):96-107. doi: https://doi.org/10.1097/FJC.0000000000000250

45. Gao W, Zhao J, Kim H, et al. Alpha-1antitrypsin inhibits ischemia reperfusion-induced lung injury by reducing inflammatory response and cell death. J Heart Lung Transplant. 2014;33(3):309315. doi: https://doi.org/10.1016/j.healun.2013.10.031

46. Moldthan HL, Hirko AC, Thinschmidt JS, et al. Alpha-1 antitrypsin therapy mitigated ischemic stroke damage in rats. $J$ Stroke Cerebrovasc Dis. 2014;23:e355-363.

doi: https://doi.org/10.1016/j.jstrokecerebrovasdis.2013.12.029

47. Guttman O, Baranovski BM, Schuster R, et al. Acute-phase protein alpha-1 antitrypsin: diverting injurious innate and adaptive immune responses from non-authentic threats. Clin Exp Immunol. 2015;179(2):161-172. doi: https://doi.org/10.1111/cei.12476

48. Lewis EC, Shapiro L, Bowers OJ, Dinarello CA. Alphalantitrypsin monotherapy prolongs islet allograft survival in mice. Proc Natl Acad Sci USA. 2005;102(34):12153-12158. doi: https://doi.org/10.1073/pnas.0505579102

49. Lewis EC, Mizrahi M, Toledano M, et al. Alpha-1antitrypsin monotherapy induces immune tolerance during islet allograft transplantation in mice. Proc Natl Acad Sci USA. 2008;105(42):16236-16241.

doi: https://doi.org/10.1073/pnas.0807627105

50. Shindo Y, Kanak MA. Total pancreatectomy with islet autotransplantation: recent updates and outcomes. Curr Opin Organ Transplant. 2017; 22(5): 444-451.

doi: https://doi.org/10.1097/MOT.0000000000000451

51. Yusen RD, Edwards LB, Kucheryavaya AY, et al. The registry of the International Society for Heart and Lung Transplantation: thirty-first adult lung and heart-lung transplant report--2014; focus theme: retransplantation. J Heart Lung Transplant. 2014;33(10):1009-1024.

doi: https://doi.org/10.1016/j.healun.2014.08.004

52. Banga A, Gildea T, Rajeswaran J. The natural history of lung function after lung transplantation for alpha(1)-antitrypsin deficiency. Am J Respir Crit Care Med. 2014;190:274-281. doi: https://doi.org/10.1164/rccm.201401-0031OC

53. Pott GB, Beard KS, Bryan CL, Merrick DT, Shapiro L. Alpha-1 antitrypsin reduces severity of pseudomonas pneumonia in mice and inhibits epithelial barrier disruption and pseudomonas invasion of respiratory epithelial cells. Front Public Health. 2013;1:19. doi: https://doi.org/10.3389/fpubh.2013.00019

54. Kaner Z, Ochayon DE, Shahaf G, et al. Acute phase protein alpha1-antitrypsin reduces the bacterial burden in mice by selective modulation of innate cell responses. I Infect Dis. 2015;211(9):1489-1498.

doi: https://doi.org/10.1093/infdis/jiu620
55. Lieberman J. Augmentation therapy reduces frequency of lung infections in antitrypsin deficiency: a new hypothesis with supporting data. Chest. 2000;118(5):1480-1485. doi: https://doi.org/10.1378/chest.118.5.1480

56. Griese M, Latzin P, Kappler M, et al. Alpha-1 antitrypsin inhalation reduces airway inflammation in cystic fibrosis patients. Eur Respir J. 2007;29(2):240-250. doi: https://doi.org/10.1183/09031936.00047306

57. Needham M, Stockley RA. Exacerbations in alpha-1 antitrypsin deficiency. Eur Respir J. 2005;25(6):992-1000. doi: https://doi.org/10.1183/09031936.05.00074704

58. Campos MA, Alazemi S, Zhang G, et al. Exacerbations in subjects with alpha-1 antitrypsin deficiency receiving augmentation therapy. Respir Med. 2009;103(10):1532-1539. doi: https://doi.org/10.1016/j.rmed.2009.04.008

59. Dirksen A, Piitulainen E, Parr DG, et al. Exploring the role of CT densitometry: a randomised study of augmentation therapy in alpha-1 antitrypsin deficiency. Eur Respir J. 2009;33(6):13451353. doi: https://doi.org/10.1183/09031936.00159408

60. Calverley PM, Anderson JA, Celli B, et al. Salmeterol and fluticasone propionate and survival in chronic obstructive pulmonary disease. N Engl J Med. 2007;356:775-789. doi: https://doi.org/10.1056/NEJMoa063070

61. Dawkins P, Wood A, Nightingale P, Stockley R. Mortality in alpha-1 antitrypsin deficiency in the United Kingdom. Respir Med. 2009;103(10):1540-1547. doi: https://doi.org/10.1016/j.rmed.2009.04.004

62. Hill AT, Campbell EJ, Hill SL, Bayley DL, Stockley RA. Association between airway bacterial load and markers of airway inflammation in patients with stable chronic bronchitis. Am J Med. 2000;109(4):288-295. doi: https://doi.org/10.1016/S0002-9343(00)00507-6

63. Shin MS, Ho KJ. Bronchiectasis in patients with alpha-1 antitrypsin deficiency. A rare occurrence? Chest. 1993;104(5):1384-1386. doi: https://doi.org/10.1378/chest.104.5.1384

64. Scott JH, Anderson CL, Shankar PS, Stavrides A. Alpha-1 antitrypsin deficiency with diffuse bronchiectasis and cirrhosis of the liver. Chest. 1977;71(4):535-538.

doi: https://doi.org/10.1378/chest.71.4.535

65. King MA, Stone JA, Diaz PT, Mueller CF, Becker WJ, Gadek JE. Alpha-1 antitrypsin deficiency: evaluation of bronchiectasis with CT. Radiology. 1996;199(1):137-141. doi: https://doi.org/10.1148/radiology.199.1.8633137

66. Maune S, Rath NF, Gorogh T, Steinert R. Genetic disposition to chronic polypoid sinusitis and alpha 1-proteinase inhibitor deficiency types [German] HNO. 1995;43(9):537-539. 
67. Chan ED, Kaminska AM, Gill W, et al. Alpha-1 antitrypsin (AAT) anomalies are associated with lung disease due to rapidly growing mycobacteria and AAT inhibits Mycobacterium abscessus infection of macrophages. Scand J Infect Dis. 2007;39(8):690696. doi: https://doi.org/10.1080/00365540701225744

68. Doring G, Krogh-Johansen H, Weidinger S, Hoiby N. Allotypes of alpha--antitrypsin in patients with cystic fibrosis, homozygous and heterozygous for deltaF508. Pediatr Pulmonol. 1994;18(1):37. doi: https://doi.org/10.1002/ppul.1950180104

69. O’Riordan K, Blei A, Rao MS, Abecassis M. Alpha-1 antitrypsin deficiency-associated panniculitis: resolution with intravenous alpha 1-antitrypsin administration and liver transplantation. Transplantation. 1997;63(3):480-482. doi: https://doi.org/10.1097/00007890-199702150-00028

70. Irvine C, Neild V, Stephens C, Black M. Alpha-1 antitrypsin deficiency panniculitis. J R Soc Med. 1990;83:743-744. doi: https://doi.org/10.1177/014107689008301120

71. Geraminejad P, DeBloom JR, 2nd, Walling HW, Sontheimer RD, VanBeek M. Alpha-1 antitrypsin associated panniculitis: the MS variant. J Am Acad Dermatol. 2004;51(4):645-655. doi: https://doi.org/10.1016/j.jaad.2003.12.053

72. Gross B, Grebe M, Wencker M, Stoller JK, Bjursten LM, Janciauskiene S. New Findings in PiZZ alpha-1 antitrypsin deficiency-related panniculitis. Demonstration of skin polymers and high dosing requirements of intravenous augmentation therapy. Dermatology. 2009;218(4):370-375. doi: https://doi.org/10.1159/000202982

73. Eming SA, Martin P, Tomic-Canic M. Wound repair and regeneration: mechanisms, signaling, and translation. Sci Transl Med. 2014;6(265):265sr6. doi: https://doi.org/10.1126/scitranslmed.3009337

74. Shanmugam VK. Vasculitic diseases and prothrombotic states contributing to delayed healing in chronic wounds. Curr Dermatol Rep. 2016;5(4):270-277.

doi: https://doi.org/10.1007/s13671-016-0157-2

75. Cathomas M, Schuller A, Candinas D, Inglin R. Severe postoperative wound healing disturbance in a patient with alpha-1-antitrypsin deficiency: the impact of augmentation therapy. Int Wound J. 2015;12:601-604. doi: https://doi.org/10.1111/iwj.12419

76. Sanders CL, Ponte A, Kueppers F. The effects of inflammation on alpha-1 antitrypsin levels in a national screening cohort. COPD. 2018;15(1):10-16. doi: https://doi.org/10.1080/15412555.2017.1401600

77. Dahl M, Tybjaerg-Hansen A, Lange P, Vestbo J, Nordestgaard BG. Change in lung function and morbidity from chronic obstructive pulmonary disease in alpha-1 antitrypsin MZ heterozygotes: A longitudinal study of the general population. Ann Intern Med. 2002;136(4):270-279.

doi: https://doi.org/10.7326/0003-4819-136-4-200202190-00006
78. Hersh CP, Dahl M, Ly NP, Berkey CS, Nordestgaard BG, Silverman EK. Chronic obstructive pulmonary disease in alpha1-antitrypsin PI MZ heterozygotes: a meta-analysis. Thorax. 2004;59(10):843-849.

doi: https://doi.org/10.1136/thx.2004.022541

79. Albes B, Bayle-Lebey P, Bazex J, Lamant L. Panniculitis revealing alpha-1 antitrypsin deficiency. Report of 3 cases [French]. Ann Med Interne. 2001;152:502-506.

80. Wewers MD, Casolaro MA, Sellers SE, et al. Replacement therapy for alpha-1antitrypsin deficiency associated with emphysema. $N$ Engl J Med. 1987;316:1055-1062. doi: https://doi.org/10.1056/NEJM198704233161704

81. Legge M, Duff GB, Potter HC, Hoetjes MM. Maternal serum alpha-1 antitrypsin concentrations in normotensive and hypertensive pregnancies. J Clin Pathol. 1984;37(8):867-869. doi: https://doi.org/10.1136/jcp.37.8.867

82. Kolialexi A, Tsangaris GT, Sifakis S, et al. Plasma biomarkers for the identification of women at risk for early-onset preeclampsia. Expert Rev Proteomics. 2017;14(3):269-276. doi: https://doi.org/10.1080/14789450.2017.1291345

83. Baranovski BM, Ozeri E, Shahaf G, et al. Exploration of alpha-1 antitrypsin treatment protocol for islet transplantation: dosing plan and route of administration. J Pharmacol Exp Ther. 2016;359(3); 482-490. doi: https://doi.org/10.1124/jpet.116.236067 